\title{
Dinâmicas regionais de mercado de trabalho: uma análise a partir Cidade de Santa Cruz do Sul (RS)
}

\author{
Regional dynamics and labor market: An Analysis from the City \\ of Santa Cruz do Sul (RS)
}

Marco André Cadoná

César Hamilton Góes

Universidade de Santa Cruz do Sul - UNISC - Santa Cruz do Sul - Rio Grande do Sul - Brasil

\begin{abstract}
Resumo: $\mathrm{O}$ artigo analisa como dinâmicas regionais de desenvolvimento condicionam a organização dos mercados de trabalho, mas, também, as condições de trabalho das pessoas que vivem do trabalho. Tomando como referência empírica pesquisa realizada na cidade de Santa Cruz do Sul (RS), cuja economia é fortemente dependente da presença de indústrias fumageiras, atenta-se para o modo como as particularidades regionais contribuem para a definição das formas de empregabilidade e de uso da força-de-trabalho, mas, também e inclusive, das formas de desemprego.
\end{abstract}

Palavras-chave: Dinâmicas regionais. Mercado de trabalho. Emprego. Desemprego. Condições de trabalho.

Abstract: This article analyzes the regional development dynamics affect the organization of labor markets, but also the working conditions of people living labor. Taking as reference empirical research conducted in the city of Santa Cruz do Sul (RS), whose economy is heavily dependent on the presence of tobacco industries, attentive to how regional differences contribute to the definition of the forms of employ ability and use strength-of-work, but also and even the forms of unemployment.

Keywords: Regional dynamics. Labor market. Employment. Unemployment. Working conditions. 


\section{Introdução}

A cidade de Santa Cruz do Sul está localizada numa região do Rio Grande do Sul cuja principal característica é o histórico vínculo econômico, político, sociocultural com a produção do tabaco: na "região fumicultora de Santa Cruz do Sul" encontra-se o maior complexo agroindustrial de tabaco do mundo (Vogt, 1997) e, especificamente na cidade de Santa Cruz do Sul, está localizado o maior complexo beneficiador de fumo em folha, contando com a presença de grandes indústrias fumageiras, tais como a Souza Cruz, a Philip Morris, a Alliance One, a Japan International Tobacco.

A presença desse complexo beneficiador de tabaco não somente coloca o município de Santa Cruz do Sul numa relação de dependência econômica com a indústria fumageira, mas, também, o próprio mercado de trabalho da cidade tem uma dinâmica que, em grande parte, expressa as necessidades colocadas pela indústria fumageira.Assim, por exemplo, uma análise dos dados do CAGED (Cadastro Geral de Empregados e Desempregados) indica que, nos primeiros semestres de cada ano, o número de pessoas que são empregadas em Santa Cruz do Sul é significativamente maior do que o número de pessoas que são demitidas, enquanto que nos segundos semestres a situação se inverte, ou seja, o número de pessoas demitidas é significativamente maior do que o número de pessoas que são admitidas. A título de exemplo, no período entre 2010 e 2013, em média foram admitidas 18.559 pessoas e demitidas 11.463 pessoas nos primeiros semestres; enquanto que nos segundos semestres, em média foram admitidas 11.492 pessoas e demitidas 17.057 pessoas (BRASIL, 2014). Ora, não é coincidência que, justamente nos primeiros semestres a indústria fumageira recebe $o$ tabaco dos agricultores para o processamento industrial, contratando, então, trabalhadores temporários (conhecidos na região de "safristas") que permanecem empregados até os meses de julho/agosto, quando termina o período de processamento industrial do tabaco.
Assim, o presente artigo apresenta dados de pesquisa realizada durante 2013 com o objetivo de analisar as condições de inserção e de permanência de trabalhadores que atuam no mercado de trabalho de Santa Cruz do Sul. Ao tomar esses dados como referência empírica da análise, atenta-se para o modo como as particularidades regionais contribuem para a definição não somente das formas de empregabilidade e de uso da força-de-trabalho, mas, também e inclusive, das formas de desemprego.

\section{Aspectos da dinâmica recente dos mercados de trabalho no Brasil}

A análise da dinâmica dos mercados de trabalho no Brasil ganhou importância, principalmente a partir das duas últimas décadas do século $X X$, em virtude do processo de reestruturação neoliberal do capitalismo no País. Para as pessoas que vivem do trabalho no País, aquele processo de reestruturação do capitalismo teve diferentes e significativas implicações, não somente por que impulsionou alterações nas formas de inserção nos processos de trabalho (em decorrência das transformações nos modos de organização da produção e do trabalho promovidas pelas empresas capitalistas), mas, também, por que provocou alterações nos mercados de trabalho, promovendo relações de trabalho não raras vezes comprometidas com uma maior precarização (desemprego, formas inseguras de empregos, comprometimento da renda, formas flexíveis de contratação do trabalho).

É importante notar, nesse sentido, que durante a década de 1990 um projeto neoliberal de reestruturação do capitalismo tornou-se uma referência importante na orientação das políticas governamentais no Brasil (grifos dos autores).O que significa dizer que, naquela década, um conjunto de pressupostos do ideário neoliberal - abertura comercial, privatização de empresas estatais, transferência para a iniciativa privada de serviços até então realizados pelo Estado, eliminação das restrições para investimentos estrangeiros, liberalização financeira, desregulamentação 
econômica e trabalhista (maior flexibilidade na legislação trabalhista), focalização e seletividade na efetivação das políticas sociais, política de estabilização da economia (o controle do déficit público e da inflação) - tornaram-se hegemônicos junto às forças sociais e políticas que estiveram no comando dos governos nacionais no Brasil, visando não somente solucionar a crise econômica do País, mas, também, promover sua "integração competitiva" no processo de reestruturação do capitalismo em nível mundial (FIORI, 2002).

No final dos anos 1990 e, portanto, após uma década de governos comprometidos com reformas e políticas econômicas orientadas para o mercado, o balanço dos resultados alcançados e das perspectivas para o "capitalismo brasileiro" não era alentador. O sucesso no combate à inflação teve como custo o aumento das taxas de juros, um incontrolado endividamento (externo e interno), o comprometimento dos investimentos e dos gastos públicos e a deteriorização ainda maior da capacidade estruturante do Estado; as privatizações, as fusões e as vendas de empresas nacionais provocaram o aumento da oligopolização e da desnacionalização da economia do País (FIORI,2002); e a economia apresentou um crescimento ainda mais insignificante daquele registrado durante a chamada "década perdida" (1980): em média, a economia brasileira cresceu $1,9 \%$ ao ano durante a década de 1990, contra os 2,2\% alcançados durante a década de 1980 (CANO,2000).

Para as pessoas que vivem do trabalho, a reestruturação neoliberal do capitalismo no Brasil durante os anos noventa se manifestou através do aprofundamento do grau de precarização do trabalho, já presente no contexto da crise econômica da década de 1980 (grifos dos autores). Precarização que se expressou, considerando os dados da PED (Pesquisa de Emprego e Desemprego) realizada pelo DIEESE (Departamento Intersindical de Estatística e Estudos Socioeconômicos), através do crescimento do desemprego, do crescimento dos empregos em condição de vulnerabilidade, do comprometimento da renda dos trabalhadores, do crescimento no número de trabalhadores sem um contrato legal de trabalho (DIEESE, 2001). Nesse sentido, como afirma Pochmann (2001), o "modelo econômico" adotado durante a década de 1990 no Brasil mostrou-se "solidário com o desemprego", pois uma "nova composição da demanda agregada" (com restrições à produção industrial do País), a "reinserção externa", a reestruturação das grandes empresas, a reformulação do setor público contribuíram para a afirmação de um quadro histórico desfavorável aos empregos e favorável ao crescimento do desemprego (POCHMANN, 2001, p. 114 et. seg.).

A partir dos anos 2000, em especial a partir do governo de Luís Inácio Lula da Silva (iniciado em 2003), um contexto internacional favorável ao crescimento da economia brasileira (considere-se, em especial, o crescimento da demanda internacional por produtos primários produzidos no País) e mudanças promovidas na direção das políticas governamentais (investimento em programas de transferência de renda, políticas de incentivo ao desenvolvimento econômico que priorizaram determinados setores econômicos com maior potencial de integração no mercado de trabalho, política de recuperação do salário mínimo) permitiram que a precarização do trabalho que caracterizou a década de 1990 fosse estancada (ainda que não tenha sido revertida), observando-se, então, um período de crescimento dos empregos (com consequente diminuição do desemprego) e de recuperação do poder aquisitivo dos salários de amplos setores das classes trabalhadoras no País (MARQUES, NAKATANI, 2009).

Se essas breves considerações acerca das políticas econômicas adotadas no Brasil a partir da década de 1990 já permitem assinalar algumas implicações sobre os mercados de trabalho e sobre as pessoas que vivem do trabalho, é preciso notar, também, que a "reorganização neoliberal" do capitalismo brasileiro a partir daquela década (abertura da economia, estagnação econômica, aposta na lógica do mercado para dinamizar o desenvolvimento, redução da capacidade estruturante 
do Estado), num contexto histórico de mudanças técnico-científicas e de mundialização do capital, impulsionou processos de reestruturação produtiva nas empresas capitalistas situadas no País, com grande capacidade de transformação nos modos de trabalhar e nos modos de inserção dos trabalhadores no mundo do trabalho.

Nessa direção, não sem descontinuidades e incongruências, empresas privadas de diferentes setores econômicos promoveram processos de reestruturação produtiva, com a adoção de novas tecnologias e novas formas de organização do processo de trabalho e de produção, buscaram novas formas de organização empresarial (terceirização da produção, deslocamento da produção, importação de fases da produção etc.), perseguiram novas e mais "flexíveis" (neologismo utilizado para encobrir processos de precarização) formas de utilização da força-de-trabalho, adotaram (principalmente as grandes empresas) estratégias de competição visando atuar num contexto de mundialização do capital (ANTUNES, 1999e2013).

Evidentemente, uma análise das características do processo histórico de reestruturação do capitalismo (em nível mundial e no Brasil), ocorrido a partir das últimas décadas do século $X X$, é importante para que se identifiquem tendências gerais naquele processo. Porém, se a análise precisa estar atenta a essas tendências gerais, às uniformidades e aos padrões construídos, não pode se descuidar, igualmente, das singularidades históricas e culturais, manifestadas essas na forma como agem e reagem (diante do próprio processo de reestruturação do modo de produção capitalista) empresas, setores econômicos, instituições, classes sociais, regiões.

Se o processo histórico de reestruturação do capitalismo colocou para as regiões, para setores econômicos, para as empresas capitalistas, a necessidade de dar respostas a uma dinâmica de desenvolvimento caracterizada por profundas transformações técnico-organizacionais, por novos padrões de produção, pela mundialização, enfim, por novas lógicas de valorização do capital, é preciso compreender como essas regiões, como esses setores econômicos e como essas empresas capitalistas, com suas particularidades econômicas, socioculturais, mesmo políticas, articularam-se e estabeleceram estratégias de atuação visando enfrentar os desafios e aproveitar as oportunidades inerentes ao próprio processo de reestruturação do modo de produção capitalista. Se a análise pretende alcançar, também, o trabalho, torna-se necessário, então, ocupar-se com os condicionamentos históricos dessa articulação (das empresas, dos setores econômicos, das regiões) sobre a natureza do trabalho, sobre o ser-que-trabalha, sobre as formas de empregabilidade, sobre as formas de estruturação dos mercados de trabalho.

\section{A dinâmica do mercado de trabalho na cidade de Santa Cruz do Sul}

A partir de agora, o artigo apresenta os dados resultantes de um levantamento realizado durante 2013 na cidade de Santa Cruz do Sul com o objetivo de investigar as condições de inserção das pessoas no mercado de trabalho da cidade, mas, também, as condições de trabalho presentes nos locais onde trabalham. O levantamento realizado ocorreu através da aplicação de um formulário de pesquisa junto a 272 (duzentas e setenta e duas) pessoas com idades entre os 16 e os 59 anos e residentes na cidade de Santa Cruz do Sul. Essa amostra, que foi construída a partir dos dados populacionais do município de Santa Cruz do Sul (Censo Demográfico 2010. IBGE, 2014) e considerou a localização (bairros), a idade, o sexo e a escolaridade das pessoas que residem na cidade, permite que os dados sejam apresentados com representatividade estatística (para a população da cidade de Santa Cruz do Sul), com um nível de confiabilidade de $90 \%$ e uma margem de erro de cinco pontos percentuais (CADONÁ,2014).

Cabe notar, ainda sobre o levantamento realizado, que o formulário aplicado contemplou um conjunto de questões distribuídas nos seguintes eixos temáticos: a) perfil socioeconômico dos trabalhadores; b) situação individual no mercado de 
trabalho; c) situação individual de ocupação; d) condições de trabalho; e) relações de trabalho. Para os fins da análise apresentada neste artigo são esses dados, portanto, que serão considerados.

Em relação ao perfil socioeconômico dos trabalhadores que responderam o formulário de pesquisa, sob o ponto de vista da idade, $11 \%$ tinham idades entre os 16 e os 18 anos, $25,8 \%$ tinham idades entre os 19 e os 29 anos, $24,6 \%$ tinham idades entre os 30 e os 39 anos, $23,2 \%$ tinham idades entre 40 e os 49 anos e 15,4\% tinham idades entre os 50 e os 59 anos; sob o ponto de vista do sexo, $47,4 \%$ eram homens e $52,6 \%$ eram mulheres; no que diz respeito à escolaridade, um grupo significativo $(39,7 \%)$ tinha, no máximo, o ensino fundamental completo, sendo que apenas 5,1\% tinham o ensino superior completo (o que é muito instigante, considerando que na cidade de Santa Cruz do Sul estão localizadas duas Instituições de Ensino Superior); por fim, quanto à renda média (declarada) das famílias, 45,6\% declararam que suas famílias tinham renda média mensal de até dois salários mínimos e apenas 6,6\% declararam que suas famílias tinham renda média mensal de cinco ou mais salários mínimos (CADONÁ,2014).

No que diz respeito à situação no mercado de trabalho, embora o levantamento dos dados tenha ocorrido num período em que a indústria fumageira ainda não estava contratando os trabalhadores temporários (o levantamento foi realizado nos meses de outubro e de novembro de 2013), um dado que se destacou, sem dúvida, foi o alto índice de pessoas desempregadas. Pela importância desse dado, apresenta-se a seguir um quadro indicando a situação em que se encontravam as pessoas no momento do levantamento. Ao serem perguntados sobre "qual era a situação em que se encontravam no mercado de trabalho naquele momento", 58,1\% afirmaram que estavam trabalhando de forma permanente num local de trabalho. Por outro lado, $15,8 \%$ afirmaram que procuraram emprego nos últimos 30 dias que antecederam ao da pesquisa, mas não encontraram, e nos últimos sete dias (que antecederam ao da pesquisa) não realizaram nenhuma atividade remunerada; constituindo esses $15,8 \%$, portanto, o que o DIEESE denomina de "desemprego aberto", ou seja, a situação dos indivíduos que, em que pese terem procurado emprego num período próximo ao da pesquisa, não encontraram, não realizando, ainda, nenhuma atividade remunerada. Somam-se a esses $15,8 \%$ de pessoas pesquisadas, porém, os $14,7 \%$ que procuraram trabalho nos últimos 30 dias que antecederam ao da pesquisa e realizaram apenas ocasionalmente atividades remuneradas naquele período, constituindo o que é indicado pelo DIEESE como "desemprego oculto". Assim, somando-se esses dois índices chega-se aos 30,5\%, caracterizando-se, nesse sentido, um índice muito elevado num contexto em que as pesquisas, em nível nacional, apontavam índices menores aos 10\% de desemprego (Quadro 01).

QUADRO 01: Trabalhadores pesquisados, por condição em que se encontravam no mercado de trabalho no período de realização da pesquisa.

\begin{tabular}{|c|c|c|}
\hline $\begin{array}{c}\text { Pessoas Condição no mercado de } \\
\text { trabalho }\end{array}$ & $\mathrm{n}$ & $\%$ \\
\hline $\begin{array}{l}\text { Está trabalhando de forma permanente } \\
\text { num local de trabalho. }\end{array}$ & 158 & 58,1 \\
\hline $\begin{array}{l}\text { Procurou emprego nos últimos } 30 \text { dias, } \\
\text { não encontrou, e nos últimos sete dias } \\
\text { não realizou nenhuma atividade } \\
\text { remunerada. }\end{array}$ & 40 & $\begin{array}{l}15,8 \\
14,7\end{array}$ \\
\hline $\begin{array}{l}\text { Procurou trabalho nos últimos } 30 \text { dias e } \\
\text { neste período realizou ocasionalmente } \\
\text { atividades remuneradas. }\end{array}$ & $\begin{array}{l}09 \\
13\end{array}$ & 3,3 \\
\hline Não procurou trabalho nos últimos 30 & 02 & 0,7 \\
\hline encontrou. & 07 & 2,6 \\
\hline $\begin{array}{l}\text { Não procurou trabalho nos últimos } 30 \\
\text { dias, mas trabalhou no último ano. }\end{array}$ & & \\
\hline $\begin{array}{l}\text { Não esteve procurando trabalho e não } \\
\text { trabalhou em lugar nenhum no último ano }\end{array}$ & & \\
\hline Outro & & \\
\hline TOTAL & 272 & 100,0 \\
\hline
\end{tabular}

Fonte: CADONÁ, 2014, p. 53.

Como explicar esses índices de desemprego? Um dos fatores explicativos é a peculiaridade do município de Santa Cruz do Sul, constituído que é por uma força de trabalho temporária (safristas) e que, portanto, num determinado período do ano fica sem 
ocupação na indústria, ou procurando outra ocupação, ou realizando atividades esporádicas ou, ainda, ficando em casa na espera de um novo período de contratação na indústria.

O município de Santa Cruz do Sul é um polo migratório na região do Vale de Rio Pardo, no Rio Grande do Sul. Mulheres e homens de diferentes municípios da região se deslocam para Santa Cruz do Sul, atraídos pela possibilidade de encontrar um emprego nas indústrias fumageiras localizadas no município. Assim, os dados aqui apresentados podem estar indicando, de fato, para uma realidade marcada por um grande índice da população adulta que se encontra numa condição de grande precarização no mercado de trabalho. Uma população trabalhadora constituída por diferentes grupos: por homens e mulheres que, de fato, estão integrados no mercado de trabalho através de ocupações permanentes (emprego formal, com carteira assinada); por homens e mulheres que constituem um exército social de reserva desse primeiro grupo, com disponibilidade e condições de ocuparem os empregos formais que 0 mercado de trabalho do município disponibiliza; por homens e mulheres situados na condição de trabalhadores temporários, os safristas, e que não necessariamente disputam os empregos formais e permanentes disponíveis no mercado de trabalho do município; e, ainda, por um "exército social de reserva dos safristas", ou seja, por homens e mulheres que vivenciam o desemprego como condição permanente de suas inserções no mercado de trabalho e que disputam, anualmente, os empregos temporários que a indústria fumageira, principalmente, oferece.

Em relação à experiência de inserção no mercado de trabalho, uma primeira questão a ser destaca está relacionada com a idade em que as pessoas que responderam ao formulário começaram a atuar no mercado de trabalho: praticamente a metade $(46,1 \%)$ começou a trabalhar com menos de 16 anos; ou seja, para parcelas significativas das pessoas que vivem do trabalho nos espaços urbanos de Santa Cruz do Sul, a experiência do trabalho se inicia cedo, ainda em idade escolar (CADONÁ,2014).
A experiência no mercado de trabalho começa cedo e compreende, de modo geral, a passagem por diferentes locais de trabalho. Pois percentagens significativas das pessoas que estavam trabalhando no momento da pesquisa, desde que começaram a trabalhar já tinham trabalhado em quatro locais: $49,7 \%$ dos trabalhadores que responderam o formulário indicaram que já tinham trabalhado em quatro ou mais lugares desde que começaram a trabalhar (CADONÁ,2014, p. 57). Esse dado, por si só, é um indicador da "flexibilidade de local" que caracteriza as trajetórias das pessoas que atuam no mercado urbano de trabalho de Santa Cruz do Sul; no entanto, não é um indicador do grau de rotatividade presente nesse mercado de trabalho, pois, no caso dos trabalhadores safristas, muitos deles não trocam de local de trabalho entre um ano e outro, mas continuam trabalhando na mesma indústria, "aproveitados" que são nos processos de avaliação e de seleção que as indústrias realizam com esses trabalhadores anualmente.

Além do desemprego e da rotatividade no trabalho, o mercado urbano de trabalho de Santa Cruz do Sul também é caracterizado pelo distanciamento de parcelas significativas de direitos sociais e trabalhistas. Isso ficou evidenciado no fato de que, dos trabalhadores que responderam 0 formulário e que estavam trabalhando no momento da pesquisa, apenas $50,3 \%$ atuavam no setor privado com carteira assinada, enquanto $14,5 \%$ atuavam no setor privado sem carteira assinada e, ainda, um grupo significativo (20\%) era constituído por autônomos que trabalhavam para o público (CADONÁ,2014, p. 59-60).

É importante destacar, também que, embora a maioria dos trabalhadores que responderam 0 formulário da pesquisa estivesse trabalhando numa jornada de trabalho de 08 horas diárias, 27,3\% afirmaram que trabalhavam mais de oito horas diárias e $22,4 \%$ afirmaram que a jornada de trabalho que tinham apresentava variações, sendo às vezes menor do que oito horas diárias e em outras vezes maior. São dados, portanto, que indicam que boa parte dos trabalhadores dos espaços urbanos de Santa Cruz do 
Sul tinha jornadas flexíveis de trabalho, não raras vezes superiores àquelas que a lei determina. Também é significativo que a maioria dos trabalhadores ocupados trabalhava nos finais de semana: $36,4 \%$ afirmaram que trabalham "frequentemente" e 19,4\% afirmaram que trabalham "às vezes" nos finais de semana (CADONÁ,2014, p. 68). Trata-se de um dado significativo, que indica que para muitos trabalhadores de Santa Cruz do Sul, os sábados e os domingos, ainda que não sejam "dias de trabalho", podem ser ocupados com trabalho, atendendo às necessidades de seus locais de trabalho. Dado corroborado pela pergunta que investigou quantos dias por semana as pessoas trabalhavam: embora a maioria afirmou que trabalhava até cinco dias $(57 \%$ afirmaram que trabalhavam até cinco dias por semana), 26,7\% afirmaram que trabalhavam seis dias (o que significa que trabalhavam nos sábados) e 9,7\% afirmaram que trabalhavam sete dias por semana (CADONÁ,2014, p. 69).

Trabalha-se, muitas vezes, mais do que cinco dias por semana, mas nem por isso o salário recebido corresponde a esse volume de trabalho. Tanto é assim que a maioria dos trabalhadores que responderam o formulário afirmou que recebia até dois salários mínimos: $77,6 \%$ afirmaram que ganhavam até dois salários mínimos, enquanto que, por outro lado, apenas 1,8\% afirmaram que ganhavam mais de 10 salários mínimos (CADONÁ,2014, p. 71).

Trabalha-se, muitas vezes, mais do que cinco dias por semana, mas nem por isso o salário recebido corresponde a esse volume de trabalho. Tanto é assim que a maioria dos trabalhadores que responderam o formulário afirmou que recebia até dois salários mínimos: 77,6\% afirmaram que ganhavam até dois salários mínimos, enquanto que, por outro lado, apenas $1,8 \%$ afirmaram que ganhavam mais de 10 salários mínimos (CADONÁ,2014, p. 71).

Sob o ponto de vista das condições de trabalho, um primeiro aspecto a ser destacado no levantamento realizado está relacionado ao tipo de trabalho que as pessoas realizavam e ao modo como avaliavam esse trabalho em termos de exigências quanto ao esforço físico, ao esforço mental, ao seu caráter criativo ou monótono, às responsabilidades implicadas, ao grau de diversidade das tarefas, mesmo quanto gostavam do trabalho que realizavam. Quanto às exigências em termos de esforço físico, os trabalhadores que responderam se dividiram entre os $38,9 \%$ que afirmaram que o trabalho que realizavam não exigia nada de esforço físico e os $40,7 \%$ que afirmaram que realizavam algum tipo de trabalho que exigia muito esforço físico. Essa divisão não se observou na avaliação quanto às exigências de esforço mental, pois praticamente a metade afirmou que o trabalho que realizavam exigia muito esforço mental, enquanto que $25,5 \%$ afirmaram que não havia nenhuma exigência de esforço mental no trabalho que realizavam (CADONÁ, 2014, p. 72).

O levantamento registrou que, de modo geral, havia um sentimento positivo em relação ao trabalho que as pessoas realizavam. Embora muitos realizavam trabalhos repetitivos (54,3\% afirmaram que o trabalho que realizavam era "muito repetitivo"), para $38,3 \%$ o trabalho realizado era muito criativo, para $45,7 \%$ era um trabalho que compreendia muitas atividades diversificadas, para $50,3 \%$ era um trabalho muito estimulante, para $86,3 \%$ era um trabalho que exigia muita responsabilidade, para $67,1 \%$ era um trabalho que podia ser realizado com muita liberdade, para $66,3 \%$ era um trabalho onde as pessoas se sentiam muito valorizadas e, finalmente, $81,4 \%$ afirmaram que gostavam muito do trabalho que realizavam (CADONÁ,2014, p. 72).

Essa visão positiva em relação ao trabalho foi, inclusive, corroborada pelos trabalhadores quando avaliaram um conjunto de aspectos relacionados às condições de trabalho que encontravam em seus locais de trabalho. Nesse sentido, considerando-se as respostas "sempre" e "às vezes", 75,2\% afirmaram que tinham oportunidades de realizar tarefas diferentes, 45,1 que tinham oportunidades de realizar cursos de capacitação, 79,9\% que tinham oportunidades de colaborar com outros colegas, $78,5 \%$ que tinham oportunidades de receber ajuda 
dos colegas, $78,5 \%$ que tinham oportunidades de trabalhar em equipe, $66,9 \%$ que tinham oportunidades de assumir responsabilidades de liderança, 55,2\% que tinham oportunidades de sugerir mudanças para seus superiores e $71,1 \%$ afirmaram que tinham oportunidades de compreender todo 0 processo de trabalho (CADONÁ,2014, p. 72).

Esse conjunto de dados é, certamente, resultado de uma ética de valorização do trabalho que, considerando a região de Santa Cruz do Sul, sua colonização alemã, o valor dado ao trabalho na tradição da região, pode ser expressivo dessa cultura de trabalho que a caracteriza. Note-se, também, como afirmado anteriormente, que $77,6 \%$ desses trabalhadores ganhavam até dois salários mínimos, o que é um indicador, também, que na avaliação do trabalho que realizavam a remuneração não era considerada como uma questão condicionante de suas representações acerca de seus trabalhos. Não se trata de afirmar que estavam satisfeitos com o que ganhavam pelo trabalho que realizavam, mas de observar que a realidade analisada compreendia uma ética de valorização do trabalho que condicionava as visões dos trabalhadores em relação aos seus trabalhos, inclusive relativizando a importância de condições adversas que encontravam em seus cotidianos de trabalho.

Essas contradições foram corroboradas pelas respostas dos trabalhadores às questões que investigaram as condições objetivas de trabalho como, por exemplo, se trabalhavam em pé, se trabalhavam em postura desgastante, se realizavam atividades repetitivas, se levantavam objetos pesados, se corriam riscos em seus locais de trabalho, se o local onde trabalhavam tinha muito barulho. Se consideradas as respostas "sempre" e "às vezes", 84,6\% trabalhavam de pé, 66,7\% trabalhavam em posturas desgastantes, 76,6\% realizavam atividades repetitivas e monótonas, 46,3\% levantavam ou deslocavam objetos pesados, 30,2\% ficavam em locais com riscos de quedas e $37,7 \%$ trabalhavam em locais com muito barulho (CADONÁ,2014, p. 74).
Há de se destacar, também, que os trabalhadores pesquisados atuavam em locais onde determinadas garantias trabalhistas (como, por exemplo, alimentação, transporte, prêmio por produtividade, férias, seguro-saúde, mesmo décimo terceiro) nem sempre estavam asseguradas. Assim, a metade não tinha acesso nem à refeição e nem a transporte nos locais onde trabalhavam; 92,1\% não acessavam creche a partir dos seus locais de trabalho; 83,5\% não trabalhavam em locais que premiavam por aumento de produtividade; 37,6\% não recebiam décimo terceiro salário; $41 \%$ não tinham férias; 76,9\% não tinham acesso a seguro-saúde e $83,8 \%$ não tinham acesso a seguro-odontológico (CADONÁ,2014, p. 76).

Por fim, é importante considerar apenas alguns dados relacionados à consciência de pertencimento à classe trabalhadora, a um coletivo que, afinal, no conjunto de relações sociais de produção presentes nas formações sociais capitalistas, participam do processo de valorização do capital na condição de trabalhadores. Nessa direção, foram propostas para as pessoas que se encontravam ocupadas no período da pesquisa apenas duas questões: se estavam filiados em algum sindicato e se consideravam importante ter representação sindical. O levantamento indicou que a maioria dos trabalhadores não estava filiada a sindicatos: $27,3 \%$ afirmaram que eram filiados a sindicatos e $72,7 \%$ afirmaram que não estavam filiados em nenhum sindicato.Em que pese não estarem filiados em sindicatos, as pessoas que responderam o formulário de pesquisa entendem que o sindicato é uma importante instituição de representação dos interesses dos trabalhadores: $65,5 \%$ afirmaram que consideravam importante ter representação sindical, enquanto 30,9\% afirmaram que não consideravam importante ter tal representação (CADONÁ,2014, p. 76-77).

\section{Considerações finais}

Este artigo apresentou uma análise das condições de trabalho que as pessoas que vivem do trabalho encontram na cidade de Santa Cruz do 
Sul.Como afirmado ainda na introdução, o mercado de trabalho no Brasil apresentou mudanças significativas nas últimas décadas. Depois de um longo período de estruturação dos mercados urbanos de trabalho, dentro dos quadros históricos da industrialização que caracterizou a economia do País especialmente no período entre 1950 e 1970, durante a década de 1980 a crise do padrão de desenvolvimento capitalista adotado pelo regime autoritário-militar iniciou um processo de desestruturação dos mercados de trabalho que se estendeu até o início da década de 2000.

Para parcelas significativas das pessoas que vivem do trabalho no Brasil, portanto, as últimas décadas do século $X X$ foram caracterizadas por um intenso processo de precarização, expresso através de altas taxas de desemprego, da enorme participação do mercado informal na constituição das ocupações, na corrosão do poder aquisitivo dos salários, no distanciamento em relação à legislação de proteção social e trabalhista, ao próprio enfraquecimento (decorrente também da desestruturação dos mercados de trabalho) da representação político-social dos trabalhadores (dos sindicatos).

A partir da década de 2000, em especial a partir do segundo governo de Luís Inácio Lula da Silva (2007, portanto), alguns indicadores do processo de precarização das condições de vida e de trabalho das pessoas que vivem do trabalho no Brasil foram estancados e, inclusive, revertidos. crescimento da economia criou condições favoráveis para que um maior número de empregos (formais) fosse criado, diminuindo significativamente 0 desemprego e, inclusive, a participação do mercado informal na constituição das ocupações do País; as políticas de distribuição de renda executadas pelos governos nacionais permitiram uma melhora significativa da renda de parcelas significativas das pessoas que vivem do trabalho, pois, além das ações de transferência direta de renda (bolsa família), implicaram ações que resultaram na melhora do poder aquisitivo dos salários; o aumento dos empregos formais (com suas implicações sobre os empregos informais) garantiram um maior acesso a direitos garantidos pela legislação social e trabalhista do País, em que pese as ofensivas (do governo e da burguesia no País) no sentido de "flexibilizar as relações de trabalho" (um eufemismo para disfarçar o interesse em diminuir os "custos" com o trabalho no País, tirando direitos sociais e trabalhistas duramente conquistados pelos trabalhadores).

Nesse sentido, a análise apresentada permite uma reflexão sobre a complexidade dos mercados de trabalho no Brasil. Pois, em que pese o período favorável aos empregos formais e às melhores condições salariais, que caracteriza a situação brasileira especialmente a partir da segunda metade da década de 2000, os dados apresentados indicam que parcelas significativas das pessoas que estão inseridas no mercado de trabalho em Santa Cruz do Sul estão desempregadas. Como apontado no artigo, $30,5 \%$ das pessoas que responderam ao formulário da pesquisa a partir da qual este artigo foi elaborado estavam, no período da pesquisa, desempregadas (desemprego aberto e desemprego oculto). São dados instigantes, pois eles não contrariam os dados nacionais que apontam índices bem menores de desemprego, mas sinalizam características específicas de um mercado de trabalho que historicamente se estruturou assentado em ocupações precárias, temporárias, típicas da condição de sazonalidade que o principal segmento de atividade econômica da região de estudo, o setor industrial fumageiro, há muito já naturalizou na referida região.

Como já foi indicado, o levantamento foi realizado nos meses de outubro e novembro de 2013. Ora, trata-se de um período em que as indústrias fumageiras não estão contratando os trabalhadores safristas. Assim, o alto índice de desemprego apontado pela pesquisa aponta para essa realidade, uma realidade caracterizada pela "cultura do aleatório", como define Castel (1998, p. 7) para dizer da situação de trabalhadores e trabalhadoras que alternam tempos de atividade e tempos de inatividade. Em Santa Cruz do Sul, uma parcela significativa de trabalhadores e de trabalhadoras vive 
nessa condição, atuando na indústria fumageira por quatro, cinco, às vezes seis, sete meses e, no restante do ano, fazem bico, ficam desempregadas, ficam esperando a próxima safra.

O mercado de trabalho de Santa Cruz do Sul, nesse sentido, se constituiu historicamente dessa forma. Existem os permanentes e existem os safristas (os temporários). Numa dinâmica que se altera no tempo e que, no caso específico da indústria fumageira, nas últimas décadas tem implicado redução dos permanentes e aumento dos safristas.

O desemprego, nesse sentido, em Santa Cruz do Sul, tem naturezas diversas. Para alguns, ele é um desemprego temporário, pois convive com a perspectiva do emprego temporário, assegurado anualmente para um grupo de trabalhadores; para outros, ele expressa o desequilíbrio permanente entre oferta e demanda por trabalho, tendo uma condição temporal que não é definida, que pode cessar através do acesso aos empregos temporários, mas que pode se estender mesmo quando chega o tempo desses. $E$, o que é instigante, essa é uma condição que cria, também, diferentes exércitos sociais de reserva: existem trabalhadores que disputam os empregos permanentes, disponibilizados não somente pela indústria fumageira, mas, também, por outras empresas e outros setores da economia; e existem trabalhadores que, inclusive pelas condições inseguras que possuem para disputar vagas no mercado de trabalho, disputam os trabalhos temporários. É uma inclusão que se manifesta com diferentes faces, muitas delas com expressões marcadas por intensa precarização.

Mas a pesquisa apresentou outros dados, relacionados às trajetórias dos trabalhadores e das trabalhadoras no mercado de trabalho, às suas "representações" acerca dos locais de trabalho onde estão atuando, às condições de trabalho e de acesso a determinados direitos trabalhistas. São dados que indicam realidades contraditórias: em que o trabalho é, ao mesmo tempo, valorizado e desvalorizado; em que os locais de trabalho são, ao mesmo tempo, agradáveis e indesejados; em que as possibilidades de realização através do trabalho são, ao mesmo tempo, assinaladas e negadas. Assim, por exemplo,parcelas significativas dos trabalhadores ocupados afirmaram que, nos seus locais de trabalho, se sentiam valorizados, afirmando, também, que gostavam do trabalho que realizavam; mas, por outro lado, a grande maioria ganhava até dois salários mínimos e muitos trabalhavam além da jornada de trabalho definida em lei; os locais de trabalho eram considerados locais "onde se realiza atividades diversas", "onde se tem espaço de autonomia", "onde se pode dar sugestões para os chefes", mas, ao mesmo tempo, muitos trabalhavam em posturas desgastantes e muitos não alcançavam direitos sociais e trabalhistas importantes para garantir condições dignas de vida e de trabalho.

O trabalho é o ponto de partida para a humanização do ser social. É a partir do trabalho que o ser humano torna-se um ser social, distinguindo-se, inclusive, de todos os outros seres animais. Na visão dos trabalhadores e das trabalhadoras pesquisadas, o trabalho é uma atividade valorizada, pois fonte de sentido para a própria existência. O trabalho abstrato encontrado, aquele que resulta das relações sociais capitalistas ou vinculadas à lógica de valorização do capital, porém, nem sempre se apresenta como atividade afirmativa e valorizadora de suas humanidades. Nesse processo histórico, poucos estão sindicalizados e, talvez, com essa atitude, expressem desconfianças legítimas em relação às formas de representação política que se desenvolvem nos espaços em que atuam. Contudo, a maioria entende que os trabalhadores e as trabalhadoras precisam ter uma representação sociopolítica, permitindo pensar que sim, "o trabalho deixou de ser o que havia sido" e que nós, seres humanos, "de repente percebemos que já não somos necessários no mundo", mas que, ao mesmo tempo e através do trabalho, é possível recuperar a positividade do trabalho e (re) afirmar a necessidade dos seres humanos no mundo. 


\section{Referências}

AFUBRA (Associação dos Fumicultores do Brasil) 2014. Fumicultura Brasil. In: www.afubra.com.br. [Acesso em 07 de dezembro 2014].

ANTUNES, Ricardo 1999. Os sentidos do trabalho: ensaio sobre a afirmação e a negação do trabalho. São Paulo: Boitempo.

(org.) 2013. Riqueza e miséria do trabalho no Brasil II. São Paulo: Boitempo.

BRASIL. Ministério do Trabalho e Emprego. Dados e Estatística. Cadastro Geral de Empregados e Desempregados - CAGED 2014. In: http://portal.mte.gov.br/caged/estatisticas.htm[Acesso em 06 de dezembro 2014].

CANO, Wilson 2000. Soberana e política econômica na América Latina. São Paulo: UNESP.

AUTOR. O mercado de trabalho e as condições de trabalho nos espaços urbanos da região fumicultora de Santa Cruz do Sul (RS): um estudo sobre precarização das relações de trabalho. Santa Cruz do Sul: UNISC (Universidade de Santa Cruz do Sul). (Relatório de Pesquisa).

CASTEL, Robert 1998. As metamorfoses da questão social: uma crônica do salário. Petrópolis: Vozes.

CHESNAIS, François 1996. A mundialização do capital. Trad. de SilvanaFinziFoá. São Paulo: Xamã.

DIEESE (Departamento Intersindical de Estudos e Estatísticas Sócio Econômicas) 2001. A situação do trabalho no Brasil. São Paulo: DIEESE.

2014. Pesquisa de emprego e desemprego (PED). In: www.dieese.com.br[Acesso em 06 de dezembro 2014].

FIORI, José Luis 2002. 60 lições dos 90: uma década de neoliberalismo. Rio de Janeiro: Record.

FREITAS, Caroline C. Schulte de 2002. O trabalho com o fumo: subjetivação e precarização na atividade das trabalhadoras safristas. Porto Alegre: UFRGS. (Dissertação de Mestrado em Psicologia Social e Institucional).

OLIVEIRA, Fabrício; NAKATANI, Paulo 2005. A política econômica do crescimento insustentável. Indicadores Econômicos FEE, Porto Alegre, v. 33, n. 1, p. 99-124.

POCHMANN, Marcio 2001. O emprego na globalização: a nova divisão internacional do trabalho e os caminhos que o Brasil escolheu. São Paulo: Boitempo.

SILVEIRA, Rogério L. Lima da 2003. Cidade, corporação e periferia urbana: acumulação de capital e segregação espacial na (re)produção do espaço urbano. Santa Cruz do Sul: EDUNISC.

SARAMAGO, José 2000. A caverna. São Paulo: Companhia das Letras.

VOGT, Olgário P 1997. A produção de fumo em Santa Cruz do Sul - RS (1849 - 1993). Santa Cruz do Sul: EDUNISC. 